\title{
Ultraviolet Nanoimprint Lithography in the Mixture of Condensable Gases with Different Vapor Pressures
}

\author{
Kenta Suzuki, Sung-Won Youn, and Hiroshi Hiroshima* \\ Research Center for Ubiquitous MEMS and Micro Engineering, \\ National Institute of Advanced Industrial Science and Technology (AIST), \\ Tsukuba, Ibaraki 305-8564, Japan, \\ *hiroshima-hiroshi@aist.go.jp
}

\begin{abstract}
UV nanoimprint lithography (UV-NIL) in condensable gases such as pentafluoropropane (PFP) has been recognized as one of the most promising methods to realize bubble-defect-free UV-NIL with low demolding forces when compared with that in ambient air and He. We have recently studied two condensable gases [trans-1-chloro3,3,3-trifluoropropene (CTFP) and trans-1,3,3,3-tetrafluoropropene (TFP)] with different vapor pressures and low global warming potentials (GWP) of $<6$. However, the resulting lithographic pattern quality in UV-NIL remains unclear using CTFP and TFP. In this work, the surface roughness of patterns fabricated using UV-NIL in the CTFP and TFP gases was investigated. In UV-NIL in a CTFP/TFP atmosphere, with an increase in the TFP fraction, the surface roughness decreased. It was also found that the linewidth of tens of nanometer size patterns can be linearly controlled by adjusting the CTFP/TFP fraction; for 70-nm-wide line patterns, the linewidth adjusting ratio was approximately $14 \%$.
\end{abstract}

Keywords: UV Nanoimprint, Condensable gas, vapor pressure

\section{Introduction}

Ultraviolet nanoimprint lithography (UVNIL) [1-4] is a recently developed technology that facilitates low-cost nanofabrication. UVNIL has a strong potential for application in production of large-scale integrated circuits and patterned media [5-8]. Bubble-free filling is an important issue to achieve highthroughput mass production using UV-NIL. Although bubble-free filling can be accomplished by performing UV-NIL under vacuum, non-vacuum processes are desirable because of their lower equipment and operation costs. For this reason, UV-NIL in a specific gas atmosphere in which bubbles are dissolved in a UV-curable resin (e.g., helium (He)) or condensed rapidly (e.g., condensable gases) have been actively studied [9-17]. Helium gas is commonly used in dispensingbased UV-NIL techniques, so-called step-and- flash UV-NIL, or jet-and-flash UV-NIL, because it has characteristics that are beneficial to high-speed nanoscale patterning processes, such as the ability to promote resin cross-linking by displacing air and rapidly diffusing into the resin $[9,10]$. However, helium also has negative attributes in UV-NIL, such as increasing the mold releasing force [11].

UV-NIL in condensable gas has been recognized as one of the most promising methods for bubble-defect-free UV-NIL [12].

We have studied 1,1,1,3,3-pentafluoropropane (PFP) in UV-NIL based on gas condensation [13-17]. Since the saturated vapor pressure of PFP at room temperature is $0.15 \mathrm{MPa}$, the pressure of PFP cannot exceed $0.15 \mathrm{MPa}$ during condensation even if it is strongly compressed. As a result, PFP is easily and completely liquefied during imprinting 
and the volume of liquid PFP is just $0.5 \%$ that of gaseous PFP. Note that neither dissolution nor diffusion of PFP in the resin affects its condensation process. Therefore, we can decrease bubble size using PFP in imprinting, regardless of the type of resin. The rates at which liquefied PFP is dissolved and diffused in the resin depend on the combination of PFP and resin. We have demonstrated that the rapid bubble-free filling of mold pattern cavities with dimensions ranging from several tens of nanometers (45-nm half-pitch) to several hundreds of micrometers can be accomplished using PFP as the environmental gas in UV-NIL and PAK-01 resins (Toyo Gosei) [18-21]. Not only is using a PFP atmosphere a potential means to achieve quick and bubble-free cavity filling, but its use is also beneficial as it decreases the viscosity of the UV-curable resin [19], decreases the amount of resin that sticks to the mold during demolding [20], and lowers the demolding forces to approximately onethird of that when performed in air [21]. However, the global warming potential (GWP) 1030 of PFP may prevent its industrial use because of environmental concerns.

We have recently studied two condensable gases with a low global warming potential (GWP) of $<6$ that have virtually zero ozone depletion potential [22-27]. One is trans-1chloro-3,3,3 -trifluoropropene (CTFP) [22-25] which has similar properties to PFP such as vapor pressure of $0.13 \mathrm{MPa}$ as shown in Table 1. The other is trans-1,3,3,3-tetrafluoropropene (TFP) [26,27] which has a higher saturated vapor pressure of $0.5 \mathrm{MPa}$ in comparison with that of PFP. Bubble-free filling of UV-NIL has been successfully demonstrated in TFP atmosphere despite it having a vapor pressure higher than the imprint pressure of $0.15 \mathrm{MPa}$ due to capillary effects [27]. UV-NIL processes using condensable gases of CTFP and TFP also provide lower demolding forces because of their very low surface tensions, as shown in Table 1 . Meanwhile, it was found that there is a difference in the pattern height shrinkage ratio (CTFP: $\sim 20 \%$, TFP: $\sim 5 \%$ ) in the case of 100 $\mu \mathrm{m}$-wide and 118-nm -high checker patterns. SEM images revealed that the quality of patterns fabricated in a CTFP environment is degraded compared with that in PFP [25]. However, details regarding the surface roughness of patterns fabricated in UV-NIL in CTFP still remain unclear.

In this work, the UV-NIL process of the condensable gases (CTFP/TFP) was further studied to investigate characteristics of the pattern quality. In our experiments, we discovered ways to control the linewidth in 70-125-nm-wide line patterns by altering the fraction of the introduced condensable gas mixture of CTFP/TFP.

Table 1. Characteristics of trans-1-chloro-3,3,3trifluoropropene (CTFP) and trans-1,3,3,3tetrafluoropropene (TFP).

\begin{tabular}{|c|c|c|}
\hline & $\begin{array}{c}\text { trans-1- } \\
\text { chloro-3,3,3- } \\
\text { trifluoroprop } \\
\text { ene (CTFP) }\end{array}$ & $\begin{array}{c}\text { trans- } \\
1,3,3,3- \\
\text { tetrafluoropr } \\
\text { opene (TFP) }\end{array}$ \\
\hline $\begin{array}{l}\text { Molecular } \\
\text { formula }\end{array}$ & $\begin{array}{c}(\mathrm{E}) \mathrm{CF}_{3-} \\
\mathrm{CH}=\mathrm{CClH}^{-}\end{array}$ & $\begin{array}{c}\text { trans- } \\
\mathrm{CF}_{3} \mathrm{CH}=\mathrm{CHF}\end{array}$ \\
\hline $\begin{array}{l}\text { Molecular } \\
\text { weight }\end{array}$ & 130 & 114 \\
\hline $\begin{array}{l}\text { Boiling point } \\
\qquad\left({ }^{\circ} \mathrm{C}\right)\end{array}$ & 19 & -19 \\
\hline $\begin{array}{c}\text { Saturated } \\
\text { vapor pressure } \\
\text { at } 25^{\circ} \mathrm{C} \\
(\mathrm{MPa})\end{array}$ & 0.129 & 0.5 \\
\hline $\begin{array}{c}\text { Ozone } \\
\text { depletion } \\
\text { potential }\end{array}$ & 0 & 0 \\
\hline $\begin{array}{l}\text { Global } \\
\text { warming } \\
\text { potential } \\
(\text { GWP) }\end{array}$ & $1-5$ & 6 \\
\hline $\begin{array}{l}\text { Surface } \\
\text { tension } \\
(\text { dyn } / \mathrm{cm})\end{array}$ & 13.3 & 8.55 \\
\hline
\end{tabular}

\section{Experimental}

A $10 \times 10 \mathrm{~mm}^{2}$ quartz mold was prepared that comprised nanopatterns with widths of $70-125 \mathrm{~nm}$ and depth of $100 \mathrm{~nm}$ (NTT AT, NIM-PHL45). The mold was treated with an anti-adhesion reagent (Gelest Aquaphobe CF) for $15 \mathrm{~min}$ [28]. A UV-curable resin (Toyo Gosei, PAK-01-60) was spin-coated on 4-inch silicon wafers. The measured thickness of the 
resin after UV curing was $110 \mathrm{~nm}$ for the film spin-coated for $120 \mathrm{~s}$ at a rotation rate of 1000 rpm. UV-NIL was carried out using a UV-NIL stepper equipped with a gas introduction system and a conformable contact mechanism known as a sample-on-flexible-thruster stage. The conditions used for UV-NIL were an imprint pressure of $0.1 \mathrm{MPa}$, contact time of $10 \mathrm{~s}$, exposure dose of $100 \mathrm{~mJ} / \mathrm{cm}^{2}$, and exposure time of $1 \mathrm{~s}$.

The introduction of the CTFP [(E)CF3$\mathrm{CH}=\mathrm{CClH}$, HFO-1233zd, CAS No. 10268765-0] and TFP (trans- $\mathrm{CF}_{3} \mathrm{CH}=\mathrm{CHF}$, HFO1234ze, CAS No. 29118-24-9) gases was controlled by adjusting the flow rates of 0 $1200 \mathrm{sccm}$ by two mass flow controllers, as shown in Fig. 1. The sample of trans-1-chloro3,3,3-trifluoro-propene (CTFP) was supplied by Honeywell International Inc. In a previously published paper [29], the delivered gas percentage was estimated to be approximately $90 \%$ at the gas flow rate of approximately $1200 \mathrm{sccm}$ in our UV-NIL system. As control samples, UV-NIL experiments in air (non-gas introduction) and in $2000 \mathrm{sccm}$ PFP were also conducted.

The surface roughness was measured using a scanning probe microscope (SPM; Hitachi High-Technologies SPA400). All images were taken in the dynamic force mode (DFM) with a commercially available carbon nanofiber (CNF) cantilever tip (Olympus OMCLAC160FS) with a spring constant of $42 \mathrm{~N} / \mathrm{m}$ and a resonance frequency of $300 \mathrm{kHz}$. The scanning area was $1 \times 0.5 \mu \mathrm{m}^{2}$.

Patterns fabricated by UV-NIL were inspected using a field-emission scanning electron microscope (SEM; Hitachi HighTechnologies S-4800) at an acceleration voltage of $0.5 \mathrm{kV}$. To evaluate the line width, the SEM images were recorded without data compression in bitmap format with a resolution size of $1280 \times 960$ pixels. The corresponding size of a pixel for the SEM images obtained at a magnification of 30,000 was $3.28 \mathrm{~nm}$. Two line patterns at a given position in each nanoimprint die were selected, and the average line widths were then calculated from the widths of the 600 scan lines analyzed with an edge detection program. The thickness of the nanoimprinted PAK-01 resin patterns was measured using a reflective film thickness monitor (Otsuka Electronics
FE-3000) with a beam spot diameter of $15 \mu \mathrm{m}$.

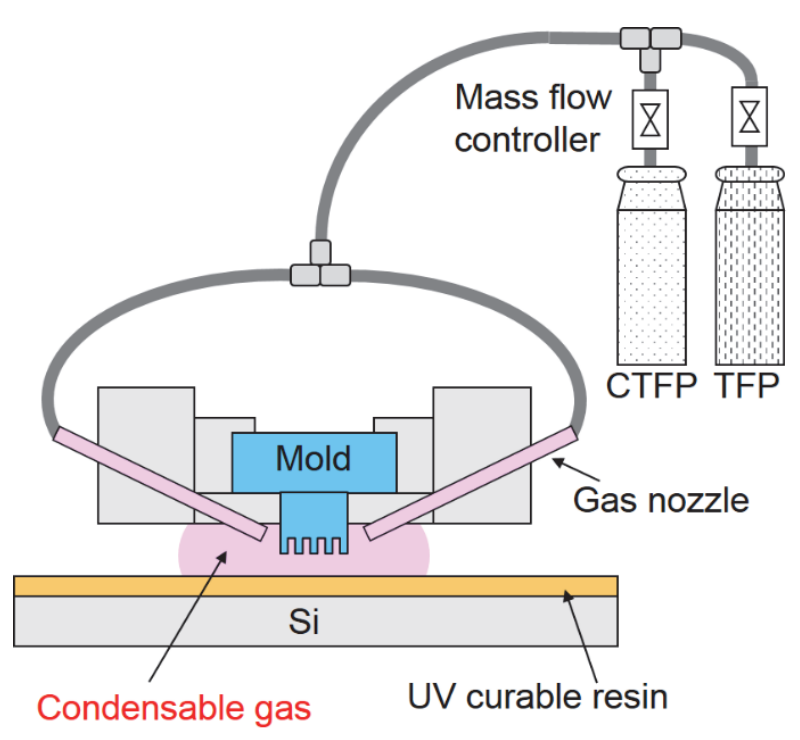

Fig. 1. Schematic of gas-introduction UV-NIL system.

\section{Results and Discussion}

\subsection{Surface roughness}

DFM was carried out to evaluate the surface roughness of the imprinted features under different atmospheric conditions. Figure 2 shows DFM topographical images of the top surfaces of features fabricated in atmospheres of air [Fig. 2(a)], PFP [Fig. 2(b)], and $\mathrm{CTFP} / \mathrm{TFP}$ gas at different gas mixing ratios [Figs. 2(c) $-2(\mathrm{~g})]$. As can be seen from the DFM images in Figs. 2(a) and 2(b), the pattern fabricated in PFP shows a more granular surface compared with that in air. PFP has a known characteristic that it is absorbed into the acrylate-based PAK-01 resin [30-31], which can result in degradation of the pattern quality with regards to line edge roughness and surface roughness, compared with that in air. As can be seen from DFM images in Figs. 2(c)( $g$ ), it is obvious that the use of a higher TFP fraction resulted in a smoother surface. A degraded surface with particulate states appears in $100 \%$ CTFP atmosphere, whereas a smooth surface was seen in $100 \%$ TFP as well as in air. 
(a)

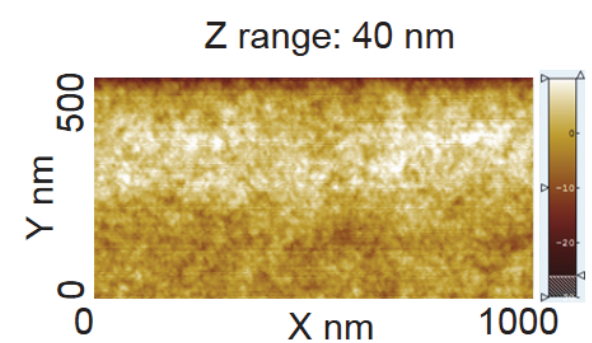

(b)

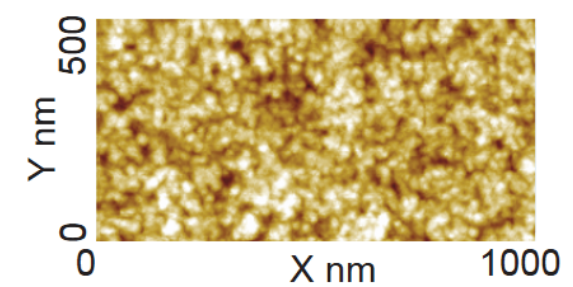

(c)

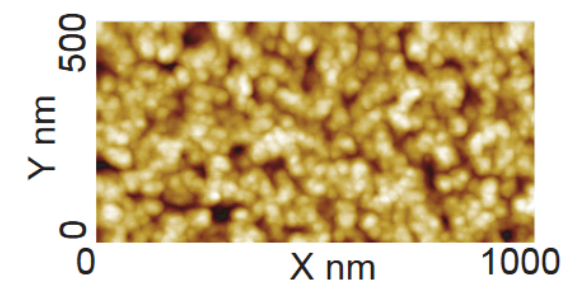

(d)

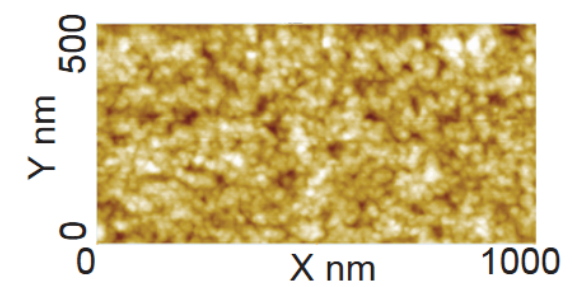

(e)

(f)

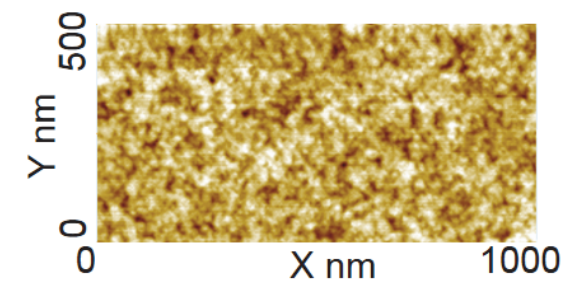

(g)
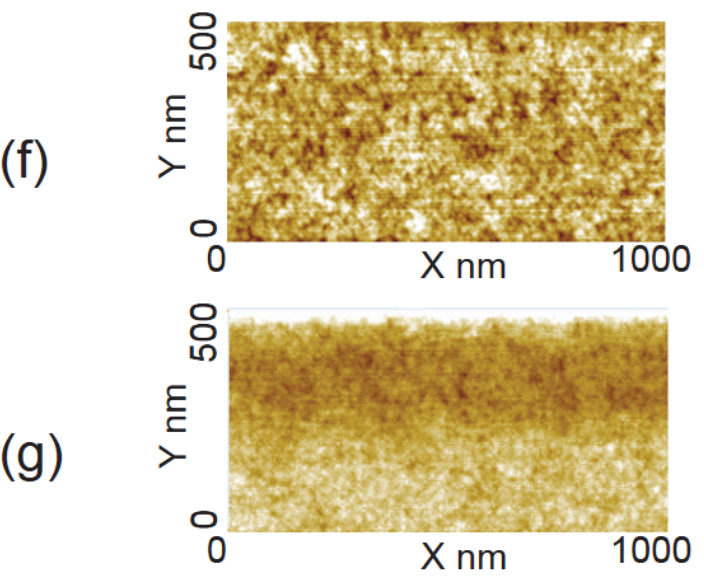

Fig. 2. DFM topographical images of the top surfaces of features fabricated in (a) air, (b) PFP, (c-g) CTFP/TFP ambient gas at different gas mixing ratios. The flow rate of the mixed gas was $1200 \mathrm{sccm}$ and the mixing ratios between CTFP and TFP were (c) $100 \%: 0 \%$, (d) $75 \%: 25 \%$, (e) $50 \%: 50 \%$, (f) $25 \%: 75 \%$, and (g) $0 \%: 100 \%$. The DFM image size was $(\mathrm{x}, \mathrm{y})=1 \times 0.5 \mu \mathrm{m}^{2}$.
The arithmetical mean roughness ( $\mathrm{Ra}$ ) was evaluated from $1 \times 0.5 \mu \mathrm{m}^{2}$ topographic DFM images of the surfaces of the imprinted pattern structures. Figure 3 shows the relationships between the surface roughness Ra and the TFP fraction in the CTFP/TFP mixture. Ra decreased from 3.41 to $0.27 \mathrm{~nm}$ (which is close to the $\mathrm{Ra}=0.26 \mathrm{~nm}$ obtained in air) with an increase in TFP fraction. The Ra values for patterns formed in a $100 \%$ CTFP atmosphere were 3 times larger than those formed in 2000 sccm PFP. We posit that the difference of surface roughness between PFP and CTFP is attributed to the different absorption of PFP and CTFP in the PAK-01 resin, or the impact of CTFP dissolution by radical reactions during UV irradiation in the UV-NIL process because of CTFP's molecular features with carbon-carbon double bonds. The Ra value of patterns for $75 \% / 25 \%$ CTFP/TFP were comparable to that in PFP. When the TFP fraction is less than $50 \%$, the $\mathrm{Ra}$ is constant within $0.5 \mathrm{~nm}$. The investigated relationship between $\mathrm{Ra}$ and CTFP/PFP fraction provides useful information for fabrication of smooth surface and high-precision structures such as optical devices.

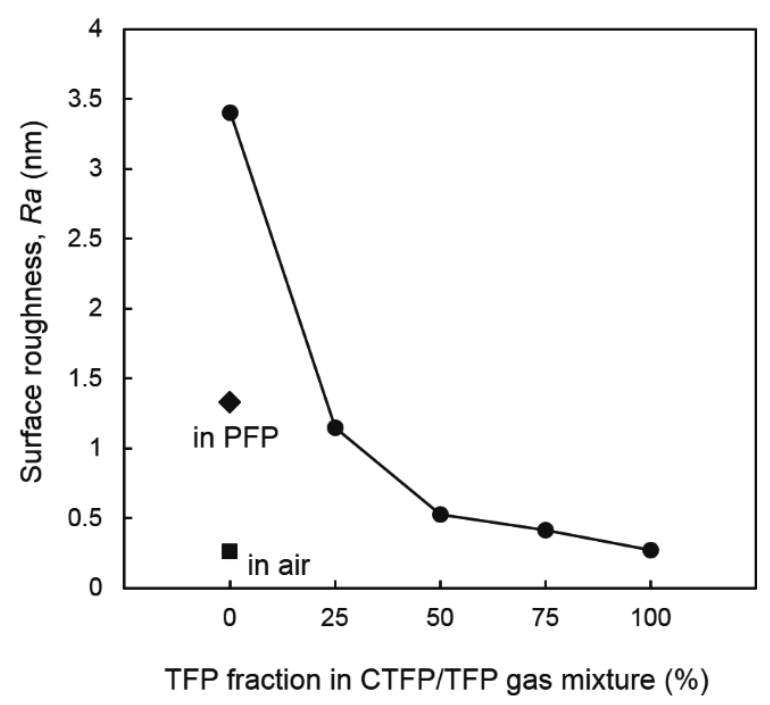

Fig. 3. Relationship between surface roughness and TFP fraction for the CTFP/TFP gas mixtures.

\subsection{Control of line widths}

Because we observed that surface roughness depends on the TFP fraction in previous experiments, we now examine the possibility 
to control linewidth in sub-100 nm patterns by UV-NIL in mixtures of CTFP/TFP. The reason for experimental control of linewidth is as follows. The line width can be adjusted by the exposure dose and developing time of the photoresist in conventional photolithography using an ArF scanner [32,33], which helps the device manufacturer to enhance flexibility in the lithography process. However, in UV-NIL features, it is difficult to adjust the linewidth in the process because the patterns are faithfully transferred by the mold structures. Therefore, we consider the linewidth control method using varying mixtures of CTFP/TFP in the process environment with the aim of providing potentially useful flexibility in the lithography process.

Figure 4 shows SEM images of nominal 70$\mathrm{nm}$ - and 125-nm- line patterns fabricated in CTFP/TFP atmospheres at different gas mixing ratios. Fine nanopatterns were successfully fabricated by UV-NIL in all gas mixtures. However, rough surfaces and degraded line edges appear in patterns fabricated in $100 \%$ CTFP, as shown in Fig. 4(a). From inspecting the SEM images shown in Figs. 4(b)-4(d), it is seen that clear line edges are fabricated without pattern deterioration when the atmospheric fraction of TFP is over $25 \%$.

Figure 5 shows the relationship between the linewidth of nominal 70-nm-wide line patterns and the TFP fraction in the CTFP/TFP mixed gas atmosphere. The line width of the nanoimprinted patterns increases almost linearly from 61.5 to $71.0 \mathrm{~nm}$ as the TFP fraction increases. It is also found that the linewidth can be controlled by adjusting the CTFP/TFP fraction, and that the linewidth adjusting range was approximately $10 \mathrm{~nm}$.

Figure 6 shows the relationship between linewidth of nominal 125-nm-wide line patterns and the TFP fraction in the CTFP/TFP mixed gas atmosphere. The line width of the nanoimprinted patterns also increases linearly from 105.9 to $126.2 \mathrm{~nm}$ increasing TFP fraction and displays a possible linewidth adjusting range of approximately $20 \mathrm{~nm}$.

Figure 7 shows the ratio of the line width shrinkage $\left(R_{\text {line }}\right)$ of patterns nanoimprinted in gas mixture of CTFP and TFP for line width of patterns nanoimprinted in CTFP 0\%: TFP $100 \%$, as a function of 'CTFP' fraction $\left(f_{C T F P}\right)$ in the CTFP/TFP gas from Figs. 5 and $6 . R_{\text {line }}$ was calculated by the following formula:

Although there was a slight deference in the linewidth shrinkage ratios between the nominal 70-nm- and 125-nm-wide line patterns, the linewidth shrinkage ratios increase almost linearly with increasing CTFP fraction. The relationship between $R_{\text {line }}$ and $f_{C T F P}$ can be described as

$$
R_{\text {line }}=0.138 f_{\text {CTFP }}
$$

It can be said that linewidth in tens of nanometer size patterns can be linearly controlled by adjusting the CTFP/TFP fraction through formula (1). (a)
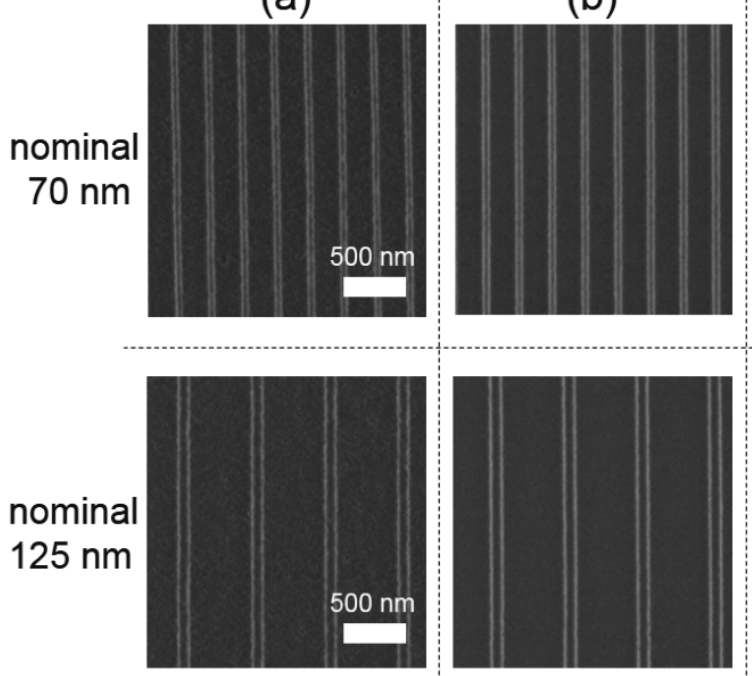

(b)

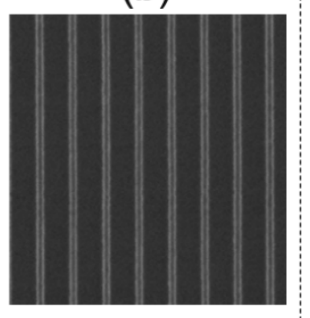

(c)

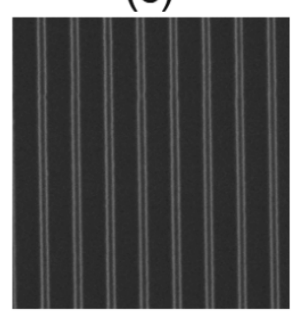

(d)
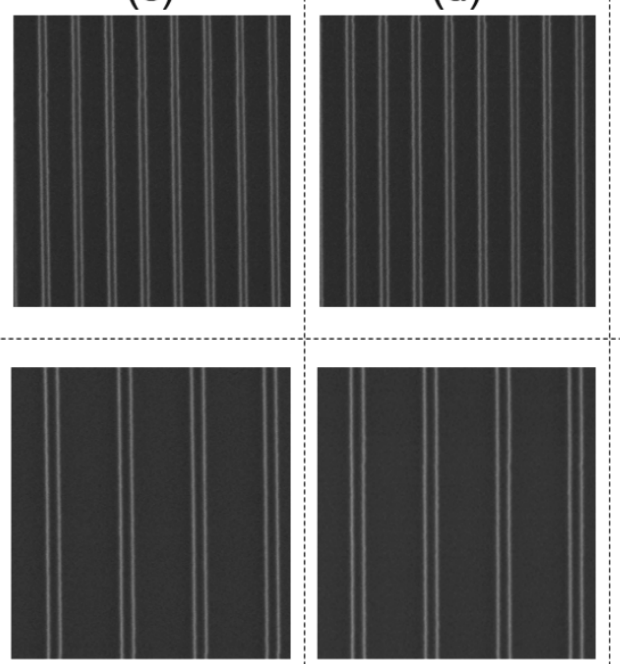

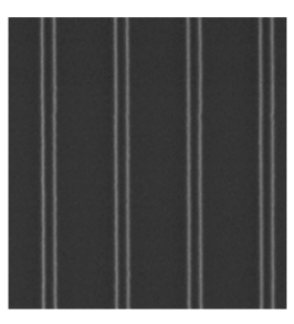

(e)
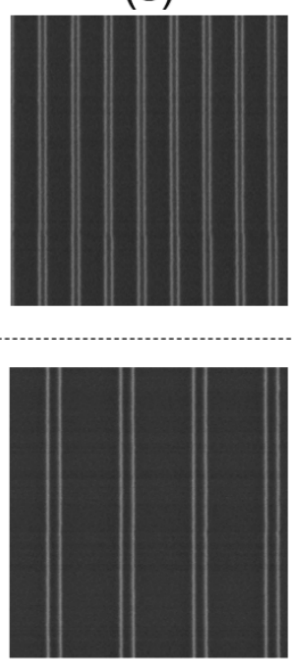

Fig. 4. SEM images of nominal $70 \mathrm{~nm}$ and $125 \mathrm{~nm}$ line patterns fabricated in CTFP/TFP atmospheres at different gas mixing ratios. The flow rate of the mixed gas was $1200 \mathrm{sccm}$ and the mixing ratios between CTFP and TFP were (a) $100 \%: 0 \%$, (b) $75 \%: 25 \%$, (c) $50 \%: 50 \%$, (d) $25 \%: 75 \%$, and (e) $0 \%: 100 \%$. 


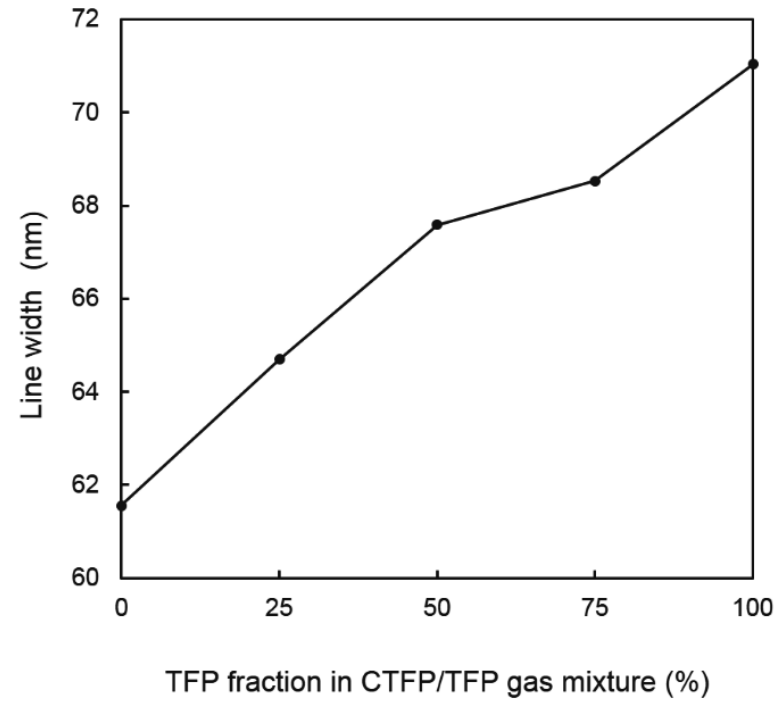

Fig. 5. Relationship between the linewidth of nominal 70-nm-wide line patterns and TFP fraction in CTFP/TFP mixed gas atmosphere.

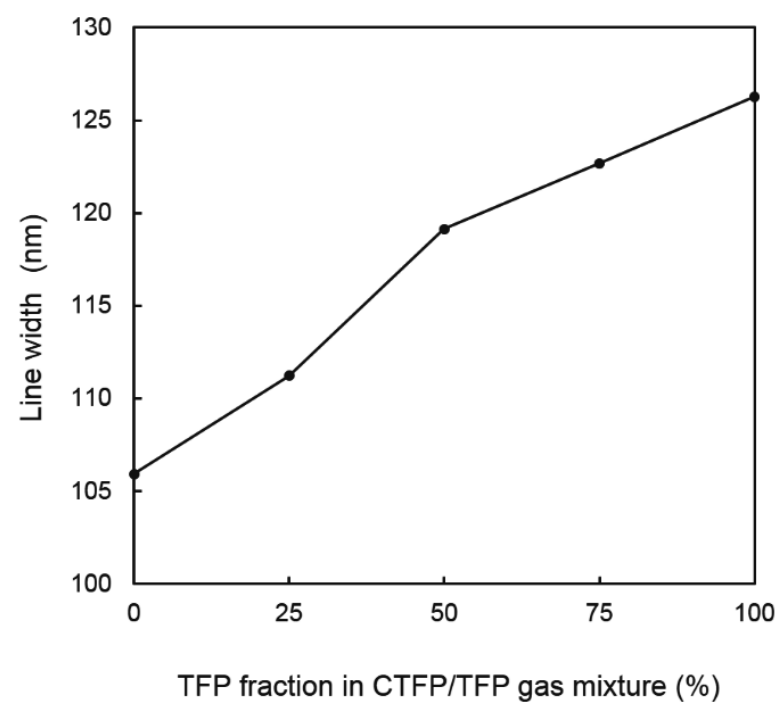

Fig. 6. Relationship between the linewidth of nominal 125-nm-wide line patterns and TFP fraction in CTFP/TFP mixed gas atmosphere.

\section{Conclusion}

In this work, the surface roughness of patterns fabricated in UV-NIL in the CTFP and TFP gases was investigated. For UV-NIL processes in a CTFP/TFP environment, increasing the TFP fraction yields a decrease in the surface roughness, $\mathrm{Ra}$, rather linearly from 3.41 to $0.27 \mathrm{~nm}$. Ra values of patterns formed in $100 \%$ CTFP were 3 times larger than those formed in $2000 \mathrm{sccm}$ PFP. It was also found that the linewidth of tens-of-nanometer sized patterns can be linearly controlled by adjusting the CTFP/TFP fraction. In the 70$\mathrm{nm}$ - and 125-nm-wide line patterns, linewidth adjusting ranges were approximately $10 \mathrm{~nm}$ and $20 \mathrm{~nm}$, respectively. The linewidth control method by varying the mixture of the CTFP/TFP atmosphere provides a potentially useful UV-NIL process for precise dimension control.

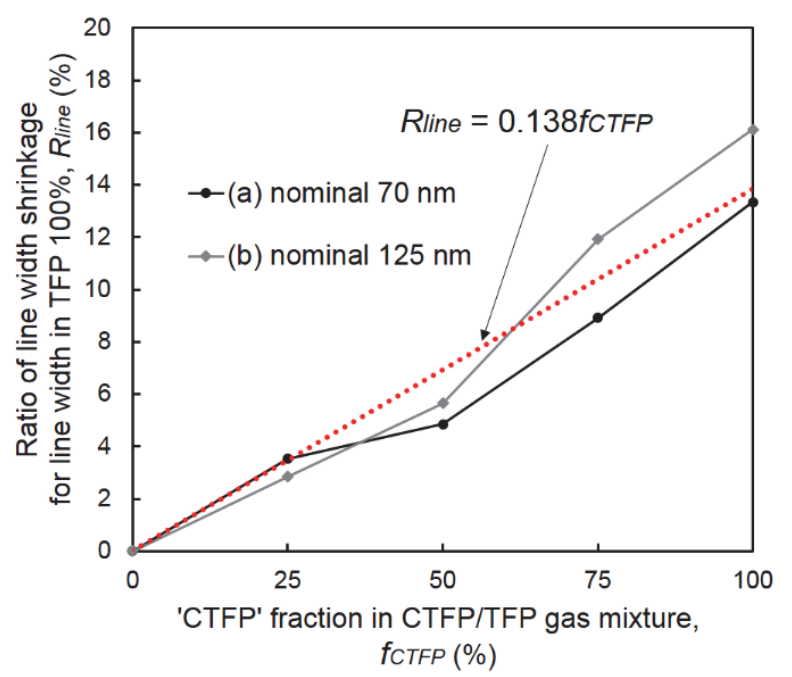

Fig. 7. Ratio of line width shrinkage patterns nanoimprinted in gas mixture of CTFP and TFP as a function of 'CTFP' fraction. (a) nominal $70 \mathrm{~nm}$ linewidth; (b) nominal $125 \mathrm{~nm}$ linewidth.

\section{References}

1. J. Haisma, M. Verheijen, K. Heuvel, and J. Berg, J. Vac. Sci. Technol. B, 14 (1996) 4124.

2. M. Colburn, S. Johnson, M. Stewart, S. Damle, T. Bailey, B. Choi, M. Wedlake, T. Michaelson, S. V. Sreenivasan, J. Ekerdt, and C. G. Willson, Proc. SPIE, 3676 (1999) 379.

3. M. Komuro, J. Taniguchi, S. Inoue, N. Kimura, Y. Tokano, H. Hiroshima, and S. Matsui, Jpn. J. Appl. Phys., 39 (2000) 7075.

4. D. J. Resnick, W. J. Dauksher, D. Mancini, K. J. Nordquist, T. C. Bailey, S. Johnson, N. Stacey, J. G. Ekerdt, C. G. Willson, S. V. Sreenivasan, and N. Schumaker, J. Vac. Sci. Technol. B, 21 (2003) 2624.

5. D. J. Resnick, W. J. Dauksher, D. Mancini, K. J. Nordquist, T. C. Bailey, S. Johnson, N. Stacey, J. G. Ekerdt, C. G. Willson, S. V. Sreenivasan, and N. Schumaker, J. Vac. Sci. Technol. B, 21 (2003) 2624.

6. G. M. Schmid, M. Miller, C. Brooks, N. 
Khusnatdinov, D. LaBrake, D. J. Resnick, S. V. Sreenivasan, G. Gauzner, K. Lee, D. Kuo, D. Weller, and X. M. Yang, J. Vac. Sci. Technol. B, 27 (2009) 573.

7. T. Higashiki, T. Nakasugi, and I. Yoneda, $J$. Micro/Nanolith. MEMS MOEMS, 10 (2011) 043008.

8. L. Wan, R. Ruiz, H. Gao, K. C. Patel, J. Lille, G. Zeltzer, E. A. Dobisz, A. Bogdanov, P. F. Nealey, and T. R. Albrecht, J. Micro/Nanolith. MEMS MOEMS, 11 (2012) 031405.

9. C. Peroz, S. Dhuey, M. Volger, Y. Wu, D. Olynick, and S. Cabrini, Nanotechnology, 21 (2010) 445301.

10. S.-W. Youn, K. Suzuki, Q. Wang, and H. Hiroshima, Jpn. J. Appl. Phys., 52 (2013) 06GJ07.

11. S. Iyoshi, M. Okada, T. Katase, K. Tone, K. Kobayashi, S. Kaneko, Y. Haruyama, M. Nakagawa, H. Hiroshima, and S. Matsui, Jpn. J. Appl. Phys., 51 (2012) 06FJ08.

12. H. Hiroshima and M. Komuro, Jpn. J. Appl. Phys., 46 (2007) 6391.

13. S.-W. Youn, Q. Wang, and H. Hiroshima, Jpn. J. Appl. Phys., 49 (2010) 06GL06.

14. H. Hiroshima and K. Suzuki, Jpn. J. Appl. Phys., 51 (2012) 06FJ10.

15. Y. Nagaoka, R. Suzuki, H. Hiroshima, N. Nishikura, H. Kawata, N. Yamazaki, T. Iwasaki, Y. Hirai, Jpn. J. Appl. Phys., 51 (2012) 06FJ07.

16. H. Hiroshima, Q. Wang, and S.-W. Youn, J. Vac. Sci. Technol. B, 28 (2010) C6M12.

17. M. Okada, M. Iwasa, H. Hiroshima, Y. Haruyama, K. Kanda, and S. Matsui, J. Vac. Sci. Technol. B, 30 (2012) 011601.

18. H. Hiroshima, H. Atobe, Q. Wang, $J$. Photopolym. Sci. Technol., 23 (2010) 45.

19. K. Suzuki, S.-W. Youn, Q. Wang, H. Hiroshima, and Y. Nishioka, Jpn. J. Appl. Phys., 51 (2012) 06FJ09.
20. K. Kobayashi, S. Kubo, H. Hiroshima, S. Matsui, M. Nakagawa, Jpn. J. Appl. Phys., 50 (2011) $06 \mathrm{GK} 02$.

21. H. Hiroshima, J. Vac. Sci. Technol. B, 27 (2009) 2862.

22. M. P. S. Andersen, E. J. K. Nilsson, O. J. Nielsen, M. S. Johnson, M. D. Hurley, and T. J. Wallington, J. Photochem. Photobiol. A, 199, 92 (2008).

23. R. J. Hulse, R. S. Basu, R. R. Singh, and R. H. P. Thomas, J. Chem. Eng. Data, 57 (2012) 3581.

24. M. P. S. Andersen, O. J. Nielsen, M. D. Hurleyc, and T. J. Wallingtonc, Phys. Chem. Chem. Phys., 14 (2012) 1735.

25. K. Suzuki, S.-W. Youn, and H. Hiroshima, to be published in Jpn. J. Appl. Phys., (2016).

26. Honeywell Technical Report, "Honeywell HFO1234ze Blowing Agent", October 2008.

27. K. Suzuki, S. W. Youn, H. Takagi, and H. Hiroshima, Proc. 25th Conf. Microelectronics Symposium (MES), Osaka, 2015, p. 261.

28. J. Taniguchi, T. Kawasaki, Y. Takano, Y. Kogo, I. Miyamoto, M. Komuro, H. Hiroshima, N. Sakai, and K. Tada, Jpn. J. Appl. Phys., 41 (2002) 4194.

29. Q. Wang, H. Hiroshima, K. Suzuki, and S. W. Youn, Jpn. J. Appl. Phys., 51 (2012) 118002.

30. S. Kaneko, K. Kobayashi, Y. Tsukidate, H. Hiroshima, S. Matsui, M. Nakagawa, Jpn. J. Appl. Phys., 51 (2012) 06FJ05.

31. S. Matsui, H. Hiroshima, Y. Hirai, and M. Nakagawa, Microelectron. Eng., 133 (2015) 134.

32. N. Sullivan, R. Dixsonb, B. Bunday, M. Mastovich, P. Knutrud, P. Fabre, and R. Brandom, Proc. SPIE, 5038 (2003) 483.

33. T. Azuma, K. Chiba, H. Abe, H. Motoki, and N. Sasaki, J. Vac. Sci. Technol. B, 22 (2004) 226. 